\title{
Not waiting for the death knell. A pilot study to examine supplementation and survivorship in a declining population of Tasmanian eastern quoll (Dasyurus viverrinus).
}

Rowena P Hamer ( $\nabla$ rhamer@tasland.org.au )

Tasmanian Land Conservancy; School of Natural Sciences, University of Tasmania https://orcid.org/0000-0002-9063-5426

Natasha Robinson

Fenner School of Environment \& Society, Australian National University

Rob Brewster

WWF-Australia

Molly Barlow

WWF-Australia

Morrigan Guinane

Trowunna Wildlife Sanctuary

Morgan Humphrey

University of Tasmania

Adrian Mifsud

Trowunna Wildlife Sanctuary

Alex S. Kutt

Tasmanian Land Conservancy; School of Natural Sciences, University of Tasmania; School of Biosciences, University of Melbourne

\section{Research Article}

Keywords: body condition, captive release, conservation translocation, Dasyuridae, dispersal, Eastern quoll, population supplementation, reintroduction, rewilding, survival, threatened species

Posted Date: February 1st, 2022

DOI: https://doi.org/10.21203/rs.3.rs-1292781/v2

License: (c) (1) This work is licensed under a Creative Commons Attribution 4.0 International License. Read Full License 
Version of Record: A version of this preprint was published at Australian Mammalogy on October 27th, 2022. See the published version at https://doi.org/10.1071/AM22011. 


\section{Abstract}

Tasmanian populations of the eastern quoll Dasyurus viverrinus, which represent the last wild stronghold of this species after its extirpation from the Australian mainland, have experienced declines of more than $50 \%$ over the past three decades. In this pilot study, we investigate the feasibility of supplementing wild populations with captive-bred individuals to attempt to reverse observed declines. Our results are encouraging, in that we recorded high initial survival and low initial dispersal of captive-bred individuals relative to previous release attempts in mainland Australia. Further work is ongoing to determine longterm survival of released individuals and the genetic and population-level impacts on local populations. Our preliminary results support the use of population supplementation as an effective conservation action, which allows for early intervention to address species declines while simultaneously testing hypotheses about their underlying causes.

\section{Introduction}

Conservation actions need to be proactive in addressing threats to wild populations in response to initial warning signs, rather than waiting for calamitous declines when recovery in the wild may be very difficult or even impossible (Geyle et al. 2018). Supplementation (also called reinforcement, re-stocking, or augmentation) has long been used for management of game and commercial species but is becoming a more prevalent approach for conservation of declining wildlife populations (Berger-Tal et al. 2020, Fischer and Lindenmayer 2000).

Like many other management interventions, supplementation is currently more likely to occur for threatened species at risk of imminent extinction, given the high cost and risk of unintended consequences (Brichieri-Colombi and Moehrenschlager 2016, Wilson et al. 2011). However, there is considerable empirical evidence demonstrating that such interventions are more likely to be successful at earlier stages of species decline (Griffith et al. 1989). This is due to: (i) the greater availability of founder individuals to establish new populations or captive-breeding programs (Fischer and Lindenmayer 2000, Weeks et al. 2011); (ii) avoidance of Allee effects and preservation of local adaptations by increasing a population size early (Weeks et al. 2011, Weeks et al. 2016); (iii) increased opportunity for transmission of adaptive behaviours from local to introduced individuals (Berger-Tal et al. 2020, Crates et al. 2017); (iv) lower risk of genetic outbreeding due to higher wild to founder ratios in target populations (Byrne and Silla 2020, Weeks et al. 2011); and (v) lower risk aversion in wildlife managers (e.g. Canessa et al. 2020).

Recent species extinctions in Australia highlight the failings of current policy and management approaches to conservation, including the need for swifter intervention once declines are detected (Martin et al. 2012, Woinarski et al. 2017). In addition, the need for decisive management action to address abrupt community and ecosystem transformations will certainly become ever more frequent under a changing climate (Lindenmayer and Taylor 2020, Maxwell et al. 2019). For example, extreme weather and wildfire events can cause severe and rapid depletion of both threatened and non-threatened fauna (Maxwell et al. 2019, Ward et al. 2020). In such contexts, supplementation may assist recovery of 
remnant populations by preventing or removing density-dependent limits on population growth, whereby recruitment cannot compensate for predation or other drivers of mortality once populations fall under a critical density threshold (e.g. Sinclair and Pech 1996). Crucially, monitoring the fate of released animals provides valuable information about threats currently acting to limit population growth (e.g. Cremona et al. 2017, Lindenmayer et al. 2018, Robinson et al. 2020), allowing targeted management interventions to address these threats.

The eastern quoll Dasyurus viverrinus is a small marsupial mesopredator once present across much of south-eastern Australia. Australian mainland populations were driven to extinction by disease, predation by introduced red fox Vulpes vulpes and human persecution (Peacock and Abbott 2014). The species persists in the island state of Tasmania where red foxes have never established; however rapid population declines of at least 50\% were observed state-wide in the ten years to 2009 (Fancourt et al. 2013), though declines varied regionally in severity and timing (C. Cunningham/DPIPWE, unpubl. data). These declines have been linked to periods of unsuitable weather and associated effects on insect prey abundance and breeding synchrony, though feral cat predation and competition, disease, poisoning, human persecution, and habitat loss may also have contributed (Fancourt 2016, Fancourt et al. 2018). Fluctuations in abundance are a characteristic of eastern quoll populations (Fancourt 2016, Peacock and Abbott 2014) but the unprecedented scale of the decay and the lack of subsequent recovery in most regions suggest the continued downward trajectory exceeds natural perturbations (Fancourt et al. 2015).

The federal conservation advice prepared for eastern quolls by the Threatened Species Scientific Committee (2015) recommends a range of management actions including: the establishment of a captive breeding program and insurance populations; reintroduction of the species to mainland Australia; and translocations within the current range, both to supplement declining populations within the core range and to increase genetic diversity in offshore Tasmanian islands. Research and management to date has focused on the former recommendations, such as establishment of captive and insurance populations (Barlow et al. 2021, Wilson et al. 2020) and reintroduction of wild populations to the Australian mainland (Portas et al. 2020, Robinson et al. 2021). In contrast, there has been no direct intervention to reverse population declines and localised extinction of eastern quolls within their extant Tasmanian range.

Given the woeful history of mammal extinctions in Australia (Woinarski et al. 2011), and the clear evidence that early management interventions have a higher chance of success with fewer risks and costs (Scheele et al. 2018), approaches to the conservation of threatened species need to look beyond eleventh-hour rescue. This pilot study aims to determine the feasibility of supplementing wild populations of eastern quolls within their extant range. We aim to determine whether released captive-bred quolls can survive and successfully breed when released into the wild in Tasmania, and the associated impacts on the abundance and genetic composition of the local wild population. This manuscript presents preliminary results on short-term survival, dispersal, and body condition of released quolls, and compares these results to previous releases of captive-bred eastern quolls on mainland Australia (Robinson et al. 2021, Wilson et al. 2020). 


\section{Methods}

\section{Study site}

Quolls were released at Silver Plains, a 6738 ha property near Interlaken in the Central Highlands of Tasmania owned and managed by the Tasmanian Land Conservancy (Figure 1). The property was selected as a low-risk release site within the core range of eastern quolls in Tasmania (Cardoso et al. 2014), with extensive suitable habitat on a gated property away from busy roads and human activity, and contiguous with larger areas of protected habitat across the Central Plateau. Eastern quolls are known to persist at the site despite an anecdotal decrease in sightings by reserve staff since the early 2000s (S. McHugh, Tasmanian Land Conservancy, pers. comm.), coinciding with the state-wide decline of the species (Fancourt et al. 2013).

Silver Plains is characterised by shrubby Eucalyptus delegatensis forest on steep, rocky dolerite hills surrounding open flat marshes dominated by short $(<5 \mathrm{~cm})$ native grasses and herbs. Prior to its purchase in 2010 the property was extensively logged, and still supports $~ 100 \mathrm{~km}$ of unsealed forestry tracks. To the east, the property is bounded by Lake Sorell, and to the north, south and west by a mix of private and public land, including the Great Western Tiers Conservation Area. Elevation at the site ranges from 800 to $1000 \mathrm{~m}$ and the climate is montane, with the closest weather station at Miena Dam (1052 m asl) recording mean annual minimum and maximum temperatures of -1.8 and 16.3 degrees.

\section{Quoll release and monitoring}

Twenty captive-bred eastern quolls ( 10 female and 10 male) were released on $9^{\text {th }}$ November 2020 . The quolls were released in one group of six and two groups of seven animals at three sites separated by 500 $\mathrm{m}$. All release sites were on an ecotone between shrubby Eucalyptus delegatensis forest and open marshes (Figure 1). Release protocols followed Robinson et al. (2020, see Appendix S1 for details). Following release, quoll survival and dispersal was monitored using a combination of VHF telemetry and trapping.

During pre-release health checks, VHF beacons (A2480, Advanced Telemetry Systems Australia) were attached to the tails of eight female and eight male quolls (four quolls were added to the project at a late stage, and additional beacons could not be sourced in time for release). Each beacon was located a minimum of twice per week, both during the day and at night. Firstly, beacons were located during daylight hours to locate den sites, and the location, type (e.g., burrow, hollow log, rock pile etc) and surrounding habitat were recorded for each den. Secondly, tracking was undertaken within four hours after dusk to confirm quoll survival and transmitter attachment (i.e., if it had left the den, or was directly observed to be active and moving). Transmitters which were recorded within the den on two subsequent nights were assumed to have detached and were retrieved where possible and reattached to quolls during live-trapping sessions. 
We conducted two live-trapping sessions, the first comprising 500 trap nights from $12^{\text {th }}-21^{\text {st }}$ November, and the second comprising 491 trap nights from $11^{\text {th }}-19^{\text {th }}$ December 2020 . We used a mixture of trap types including $22 \mathrm{~cm} \times 22 \mathrm{~cm} \times 55 \mathrm{~cm}$, and $31 \mathrm{~cm} \times 31 \mathrm{~cm} \times 70 \mathrm{~cm}$ wire cage traps and $30 \mathrm{~cm}$ diameter PVC carnivore traps, baited with meat (venison, wallaby, chicken, or Smitten ${ }^{\mathrm{TM}}$ tinned pet food). Traps were deployed along ecotones, roads, and tracks, and were moved on occasion during the surveys based on capture histories and VHF telemetry results to maximise the chances of capturing all released quolls. Trapped animals were transferred from traps into canvas handling sacks, weighed to the nearest ten grams, then assessed for body condition and transmitter status (if applicable).

Three supplementary feeding stations, were established near the three release sites, as recommended by Robinson et al. (2020), to ease the transition from captivity. Three motion-trigger infrared cameras (Reconyx HC600) were deployed at each station, with one directly above the station facing down and the other two perpendicular to each other, to aid in monitoring survivorship and general activity of the quolls and other species. Feeding stations were monitored continuously and restocked with decreasing frequency for 6 months following release (Appendix S1).

\section{Data analysis}

Data from the Silver Plains release were analysed to compare short-term (45 days post-release) survival, maximum dispersal and body condition to previous releases undertaken at Booderee NP in 2018 and 2019 (Robinson et al. 2021), using raw data supplied by N. Robinson to allow statistical comparison. We also compared the Silver Plains survival results to those obtained from three releases undertaken at Mulligans Flat, a 485 ha fenced predator-free reserve in the Australian Capital Territory (Wilson et al. 2020). Raw data for these releases were not available so comparisons are based on published estimates only. All analyses were performed in the R statistical environment ( $R$ Core Team 2020).

For survival analyses, only data from the first 45 days were used to enable direct comparisons between releases. Estimated survival curves were fitted with the Kaplan-Meier method using the 'survfit' function within the survival package (Therneau 2021), with sex (male/female) and release (Booderee NP 2018, Booderee NP 2019, Silver Plains 2020) included as covariates to visualise potential differences. Formal analyses of the influence of sex and release on survival were undertaken using Bayesian Cox proportional-hazards models. Models were fitted using the 'inla' and 'inla.surv' functions with default settings (normal priors with mean zero and variance 1,000) within the INLA package (Lindgren and Rue 2015). Best-fitting models were selected using the widely applicable information criteria (WAIC, Vehtari et al. 2017). Model effects were described as statistically significant if their $95 \%$ credible intervals did not overlap zero, and relative hazard estimates were obtained for each parameter by taking the exponential of coefficient estimates.

Following Robinson et al. (2021), a single measurement of maximum dispersal distance was obtained for each quoll using the maximum recorded straight-line distance from the release site, considering only daytime den site locations. Maximum dispersal was then modelled against release, sex and size (release 
weight, adjusted for sex by z-scaling using common standard deviation but sex-specific mean). Generalised linear models were fitted with a gamma distribution and log-link function to account for positively-skewed data, using the ' $\mathrm{glm}$ ' function from the stats package available with the base $\mathrm{R}$ environment ( $R$ Core Team 2020). Tracking duration (in days) was included in all models to adjust for increased dispersal opportunity with longer time since release. Models were compared using Akaike Information Criteria, adjusted for small sample size (AICC). Models within 2 AICc units were regarded as equivalent, in which case the most parsimonious model (with least parameters) was regarded as the top model (Burnham and Anderson 2002).

Finally, we fitted general linear mixed models to investigate the influence of release location, sex, size and time since release (z-scaled) on relative body condition (weight as a proportion of release weight). Individual quoll identification number was included as a random factor, and general linear mixed models fitted using the 'Imer' function from the Ime4 package (Bates et al. 2015). Best-fitting models were selected using AICc as above.

\section{Results}

\section{Survival}

Of the 20 quolls released at Silver Plains, two (one female and one male) were confirmed to have died within four and eight days of release, respectively. In both cases, cause of mortality could not be conclusively determined from necropsies: the male had a clear puncture wound at the nape, but PCA swabs revealed only quoll DNA. The wound may have been inflicted by another quoll or the test may have failed to amplify the aggressor's DNA. The female was found dead in the den with no apparent wounds, and the necropsy was inconclusive.

Live-trapping confirmed that fifteen quolls (75\% of the release cohort, comprising seven females and eight males) were still alive between 32 and 45 days post-release. The remaining three quolls were last recorded alive via telemetry between 11 and 21 days post-release, before the VHF beacons either fell off (two quolls) or failed (one quoll). These quolls were not subsequently recaptured during trapping surveys. In the Booderee NP releases only $40 \%(2018, n=20)$ or $45 \%(2019, n=40)$ of the cohort were known to be alive after 45 days (Robinson et al. 2021). Accounting for individuals with uncertain fate, models estimate that survival rates at Silver Plains were significantly higher than during the 2018 Booderee NP release (mean and 95\% credible interval for Silver Plains mortality risk 17\% [3-65\%] of that experienced during the 2018 Booderee NP release, Table S2), but not significantly different to the 2019 release (estimated as $98 \%$ [ $48-206 \%$ ] of the 2018 Booderee NP release). In contrast to the results of Robinson et al. (2021), who reported a marginal effect of sex on survival ( $90 \%$ credible intervals did not overlap zero, but $95 \%$ credible intervals did), we found no evidence for an effect of sex on survival across the three releases (Table S1, Figure 2a). 
Silver Plains survival rates were also higher than published estimates of survival during an initial release into a fenced sanctuary at Mulligans Flat (29\% survival after 42 days in 2016), but were roughly equivalent to or lower than subsequent releases at the same sanctuary (77\% in 2017 and $88 \%$ in 2018, Wilson et al. 2020).

\section{Dispersal}

Dispersal data was obtained from 59 quolls, of which 30 were female and 29 male. This comprised all 20 quolls released in both the Silver Plains 2020 and Booderee NP 2018 releases, and 19 of 40 quolls released at Booderee NP in 2019. At Silver Plains, the maximum dispersal distances recorded within 45 days of release were $2.3 \mathrm{~km}$ (female) and $2.5 \mathrm{~km}$ (male) from the release sites, compared to maximum dispersal distances of 7.0 and $9.5 \mathrm{~km}$ for females and males respectively in the two Booderee NP releases. As of 40 days post-release, ten quolls at Silver Plains were still using den sites within $1.0 \mathrm{~km}$ of the release site.

Consistent with the results of Robinson et al. (2021), maximum dispersal distance was positively associated with the duration of tracking (Figure 2b). In contrast, size (sex-adjusted release weight) of quolls was not included in the top model (Table S3). Model predictions confirm that release site had a significant effect on maximum dispersal distance, with quolls at Booderee NP dispersing on average 4 $\mathrm{km}$ more than quolls at Silver Plains over the 45 day tracking period (model predictions and $95 \%$ confidence intervals for maximum dispersal after 45 days are $4.5 \pm 2.3 \mathrm{~km}, 6.0 \pm 3.2 \mathrm{~km}$, and $1.3 \pm 0.5 \mathrm{~km}$ for the Booderee NP 2018, 2019 and Silver Plains 2020 releases, respectively).

\section{Body condition}

A total of 189 body mass measurements were obtained from 16 quolls ( 8 of each sex) during the Silver Plains release, 22 quolls (10 females, 11 males) during the 2019 Booderee NP release and 14 quolls ( 7 females of each sex) during the 2018 Booderee NP release.

During the Silver Plains release, maximum recorded loss of body mass at any point during the 45-day monitoring period was larger for male quolls (average maximum weight loss $18.1 \pm 2.3 \%$ of release weight) than for females (average $7.0 \pm 2.3 \%$ of release weight). This pattern is similar to that recorded in both of the Booderee NP releases: average maximum weight loss for males and females was $15.3 \pm 4.2 \%$ vs $9.9 \pm 2.7 \%$ in the 2018 release, and $13.5 \pm 2.4 \%$ vs $7.7 \pm 3.0 \%$ in 2019 , respectively.

The top-ranked model included interactions between the quadratic effect of time since release and the effects of sex and release, but did not include release or sex-adjusted release weight (Table S4). In all releases, the rate of weight loss appeared to plateau or reverse by the end of the monitoring period, however variation was high between individuals (Figure 2c). Patterns of weight loss were slightly different across releases, with the 2018 Booderee NP release showing a steeper initial decline in weight than the other two releases. Model predictions confirm that the average rate of weight loss was greater 
for male than female quolls (Figure 2c). At the end of the 45-day monitoring period, females had on average regained their release weight (averaged model predictions $103 \%$ of release weight, $95 \%$ confidence interval $96-108 \%$ ), whereas most male quolls were still below release weight (averaged model prediction $91 \%$ of release weight, $95 \%$ confidence interval $0.84-0.97$, Figure $2 c$ ).

\section{Discussion}

In the short term, captive-bred eastern quolls released at Silver Plains in Tasmania survived longer, stayed closer to release sites, and showed equivalent changes in body condition when compared to similar releases into unfenced areas of mainland Australia (Robinson et al. 2021). Differences in survival rates were clearly attributable to the absence of major threats such as red foxes Vulpes vulpes and busy roads, the key causes of mortality in mainland eastern quoll releases. Shorter observed dispersal distances may be due to the high suitability of habitat, similar climatic conditions at the captive-breeding locations and

release site, or by attraction to conspecific cues from wild quolls. The results to date from this pilot study provide good support for captive-bred releases as a viable tool for managing wild populations of eastern quolls in Tasmania.

Survival rates of quolls released at Silver Plains were higher than those recorded at Booderee NP, and relatively similar to releases into a large predator-free sanctuary with an existing quoll population (Wilson et al. 2020). Unlike these studies, we found no difference in mortality between male and female quolls, with a single mortality recorded for each sex. The high survival rate of quolls at Silver Plains is likely due to the absence of key threats. First, red foxes, which are in part responsible for the extinction of mainland Australian populations of eastern quolls (Jones and Rose 2001, Peacock and Abbott 2014) and accounted for up to $43 \%$ (14 of 33) known mortalities during the Booderee NP releases (Robinson et al. 2021), have not established in Tasmania. Many mammal reintroduction attempts from predator-free enclosures on mainland Australia have been thwarted by introduced predators (Moseby et al. 2011) and further attempts have involved moderating feral cat and fox densities in release sites to understand an appropriate background threshold for increased survivorship (Moseby et al. 2019). Second, Silver Plains was selected as the release site specifically because it is a private reserve with no public access and little vehicle traffic; vehicle collisions accounted for $20 \%$ of the known mortality at Booderee NP (Robinson et al. 2021). Road kill is a significant threat to many threatened species globally (Rytwinski et al. 2016) and is a leading cause of mortality in wild populations of the congeneric northern quoll $D$. hallucatus (Oakwood 2000).

Given the presence of wild quolls with established territories, and higher short-term survival of the release cohort, we expected increased dispersal relative to previous releases due to competition for resources such as den sites, food and mates (Christian 1970, Trochet et al. 2016). Observed dispersal distances were approximately $25 \%$ of those observed at Booderee NP over the same time period. We propose two possible explanations for this pattern, namely (i) the high availability - and therefore lack of competition for - resources such as food, shelter or potential mates (Macdonald 1983, McNab 1963); and/or (ii) the presence of wild quolls may have reduced dispersal simply because released quolls are attracted to 
conspecific cues. Such attraction has been empirically demonstrated in many species (Stamps 1988), and manually adding conspecific cues to an environment has been successfully used as a technique to limit dispersal during translocations (Berger-Tal et al. 2020). Cultural and social learning is a rarely considered but potentially significant factor in conservation biology and reintroductions (Brakes et al. 2021). Regardless of the underlying mechanism, these results have positive implications for the use of captive-bred releases as a management tool to bolster existing population of this species, as lower dispersal is often linked with lower mortality and increases the probability that released individuals will contribute to the effective size of the target population (Moseby et al. 2014, Wilson et al. 2020).

Release strategies have been shown to strongly affect body condition in multiple species (e.g. Moseby et al. 2014). Across the three releases studied here, although the rate and timing of weight loss and recovery varied, the maximum amount of weight lost and the relative body weight recorded at the end of the monitoring period were remarkably consistent. This similarity is unexpected, given the releases occurred in different seasons (March 2018, May 2019 and November 2020) and very different climates; and the potential for increased conspecific competition at Silver Plains as discussed above. These data therefore provide useful guidelines for assessing acceptable levels of weight loss for future releases of captivebred eastern quolls. Most quolls remained within $20 \%$ of release weight (44 of 51 individuals), although we recommend incorporating some assessment of body fat rather than relying on weight alone to assess whether animals should be removed from the project. For example, the three quolls which lost more than $20 \%$ of their body mass during the Silver Plains release were all large males (release weights $1.3-1.6 \mathrm{~kg}$ ) which had been consistently gorge-fed in the lead up to the release to prevent aggression in the shared free-range enclosure (author A.M., unpubl. data.) and were therefore carrying excess fat at release. All three of these quolls were never assessed as underweight according to the presence of body fat and muscle and were recaptured in a subsequent trapping approximately nine months post-release (July 2021, author R.H. unpubl. data).

The dire situation of threatened species in Australia, including the continued depletion and contemporary extinction of mammal species (Geyle et al. 2018, Woinarski et al. 2015), mean that complacency in threatened species management has little place in future conservation management. Pre-emptive approaches to species recovery are needed in environments where threats persist, to maintain populations of species beyond the confines of predator-free islands and enclosures (Dickman 2012, Evans et al. 2021). The results of this pilot study provide preliminary support for using releases of captive-bred eastern quolls to help recover wild Tasmanian populations, in that they indicate high initial survival and low initial dispersal of captive-bred individuals relative to previous release attempts. Future work that will establish whether these individuals successfully breed, and the subsequent impacts on local population density and genetic diversity and composition, will provide more insight into the feasibility of such releases as a management tool for this species. These results also complement existing research by providing data from an intermediate-risk context, whereas previous releases have been either low-risk introductions into fenced predator-free sanctuaries (e.g. Wilson et al. 2020) or highrisk re-introductions to the species' historic range with ongoing (though controlled) presence of red foxes 
(Robinson et al. 2021). Additional data across this spectrum of low to high-risk contexts would assist in characterising situations where supplementation will be an appropriate management technique.

\section{Declarations}

\section{Acknowledgements}

This pilot study was funded by the Tasmanian Land Conservancy, WWF-Australia's Rewilding Unit, the Wettenhall Environment Trust and the Mohamed bin Zayed Species Conservation Fund. We thank several key collaborators who supported this pilot study, namely Dr Karrie Rose (Taronga Conservation Society Australia), Dr Felicity Kerr (Meander Valley Veterinary Service), Chris Freeman and staff (East Coast Natureworld), Wade Anthony and staff (Devils@Cradle), Androo Kelly and staff (Trowunna Wildlife Sanctuary), Jacob Virtue and Darren Turner (Aerospec) and Belinda Wilson (Australian National University). Professor Menna Jones, Dr Glen Bain and Dr Dave Hamilton (University of Tasmania) and Dr Sam Fox, Phil Wise, and Stuart Huxtable (DPIPWE) also provided equipment, advice, and support. We are grateful to the many Tasmanian Land Conservancy staff and supporters who assisted with post-release monitoring. All work was conducted under the Department of Primary Industries, Parks, Water and Environment Animal Ethics Committee permit number 6/2020-21 and Scientific Permit TFA20240. We acknowledge and pay respect to the Tasmanian Aboriginal people and Elders - past, present, and emerging - as the traditional and original owners, and continuing custodians of the land on which we undertook this study.

\section{References}

Barlow, M. M., et al. 2021. Species distribution models for conservation: identifying translocation sites for eastern quolls under climate change. - Global Ecology and Conservation e01735.

Bates, D., et al. 2015. Fitting Linear Mixed-Effects Models Using Ime4. - Journal of Statistical Software 67: 48.

Berger-Tal, O., et al. 2020. Conservation translocations: a review of common difficulties and promising directions. - Animal Conservation 23: 121-131.

Brakes, P., et al. 2021. A deepening understanding of animal culture suggests lessons for conservation. Proceedings of the Royal Society B: Biological Sciences 288: 20202718.

Brichieri-Colombi, T. A. and Moehrenschlager, A. 2016. Alignment of threat, effort, and perceived success in North American conservation translocations. - Conservation Biology 30: 1159-1172.

Burnham, K. P. and Anderson, D. R. 2002. Model Selection and Multimodel Inference: A Practical Information-Theoretic Approach. - Springer-Verlag. 
Byrne, P. G. and Silla, A. J. 2020. An experimental test of the genetic consequences of population augmentation in an amphibian. - Conservation Science and Practice 2: e194.

Canessa, S., et al. 2020. Risk aversion and uncertainty create a conundrum for planning recovery of a critically endangered species. - Conservation Science and Practice 2: e138.

Cardoso, M. J., et al. 2014. Genetic monitoring reveals significant population structure in eastern quolls: implications for the conservation of a threatened carnivorous marsupial. - Aust. Mammal. 36: 169-177.

Christian, J. J. 1970. Social Subordination, Population Density, and Mammalian Evolution. - Science 168: 84-90.

Crates, R., et al. 2017. Undetected Allee effects in Australia's threatened birds: implications for conservation. - Emu - Austral Ornithology 117: 207-221.

Cremona, T., et al. 2017. High mortality and small population size prevent population recovery of a reintroduced mesopredator. - Animal Conservation 20: 555-563.

Dickman, C. R. 2012. Fences or Ferals? Benefits and Costs of Conservation Fencing in Australia. - In: M. J. Somers and M. Hayward (eds), Fencing for Conservation: Restriction of Evolutionary Potential or a Riposte to Threatening Processes? Springer New York, pp. 43-63.

DPIPWE 2020. TASVEG 4.0. - Tasmanian Vegetation Monitoring and Mapping Program, Natural and Cultural Heritage Division, Department of Primary Industries, Parks, Water and the Environment.

Evans, M. J., et al. 2021. The 'Goldilocks Zone' of predation: the level of fox control needed to select predator resistance in a reintroduced mammal in Australia. - Biodivers Conserv 30: 1731-1752.

Fancourt, B. A., et al. 2013. Evidence of rapid population decline of the eastern quoll (Dasyurus viverrinus) in Tasmania. - Aust. Mammal. 35: 195-205.

Fancourt, B. A., et al. 2015. Testing the Role of Climate Change in Species Decline: Is the Eastern Quoll a Victim of a Change in the Weather? - PLoS ONE 10: e0129420.

Fancourt, B. A. 2016. Diagnosing species decline: a contextual review of threats, causes and future directions for management and conservation of the eastern quoll. - Wildlife Research 43: 197-211.

Fancourt, B. A., et al. 2018. Mechanisms of climate-change-induced species decline: spatial, temporal and long-term variation in the diet of an endangered marsupial carnivore, the eastern quoll. - Wildlife Research 45: 737-750.

Fischer, J. and Lindenmayer, D. B. 2000. An assessment of the published results of animal relocations. Biological Conservation 96: 1-11. 
Geyle, H. M., et al. 2018. Quantifying extinction risk and forecasting the number of impending Australian bird and mammal extinctions. - Pacific Conservation Biology 24: 157-167.

Griffith, B., et al. 1989. Translocation as a Species Conservation Tool: Status and Strategy. - Science 245: 477-480.

Jones, M. E. and Rose, R. K. 2001. Dasyurus viverrinus. - Mammalian Species 1-9.

Lindenmayer, D. B., et al. 2018. Conservation conundrums and the challenges of managing unexplained declines of multiple species. - Biological Conservation 221: 279-292.

Lindenmayer, D. B. and Taylor, C. 2020. New spatial analyses of Australian wildfires highlight the need for new fire, resource, and conservation policies. - Proceedings of the National Academy of Sciences 117: $12481-12485$.

Lindgren, F. and Rue, H. 2015. Bayesian Spatial Modelling with R-INLA. - Journal of Statistical Software 63: 1-25.

Macdonald, D. W. 1983. The ecology of carnivore social behaviour. - Nature 301: 379-384.

Martin, T. G., et al. 2012. Acting fast helps avoid extinction. - Conservation Letters 5: 274-280.

Maxwell, S. L., et al. 2019. Conservation implications of ecological responses to extreme weather and climate events. - Diversity and Distributions 25: 613-625.

McNab, B. K. 1963. Bioenergetics and the Determination of Home Range Size. - The American Naturalist 97: 133-140.

Moseby, K. E., et al. 2011. Predation determines the outcome of 10 reintroduction attempts in arid South Australia. - Biological Conservation 144: 2863-2872.

Moseby, K. E., et al. 2014. Tailoring Release Protocols to Individual Species and Sites: One Size Does Not Fit All. - PLOS ONE 9: e99753.

Moseby, K. E., et al. 2019. Understanding predator densities for successful co-existence of alien predators and threatened prey. - Austral Ecology 44: 409-419.

Oakwood, M. 2000. Reproduction and demography of the northern quoll, Dasyurus hallucatus, in the lowland savanna of northern Australia. - Aust. J. Zool. 48: 519-539.

Peacock, D. and Abbott, I. 2014. When the 'native cat' would 'plague': historical hyperabundance in the quoll (Marsupialia : Dasyuridae) and an assessment of the role of disease, cats and foxes in its curtailment. - Australian Journal of Zoology 62: 294-344. 
Portas, T. J., et al. 2020. Baseline health and disease assessment of founder eastern quolls (Dasyurus viverrinus) during a conservation translocation to mainland Australia. - Journal of Wildlife Diseases 56: 547-559.

R Core Team 2020. R: A language and environment for statistical computing. R Foundation for Statistical Computing, Vienna, Austria. https://www.R-project.org/:

Robinson, N. M., et al. 2020. Be nimble with threat mitigation: lessons learned from the reintroduction of an endangered species. - Restor. Ecol. 28: 29-38.

Robinson, N. M., et al. 2021. Can evolutionary theories of dispersal and senescence predict postrelease survival, dispersal, and body condition of a reintroduced threatened mammal? - Ecology and Evolution 11: 1002-1012.

Rytwinski, T., et al. 2016. How Effective Is Road Mitigation at Reducing Road-Kill? A Meta-Analysis. PLOS ONE 11: e0166941.

Scheele, B. C., et al. 2018. How to improve threatened species management: An Australian perspective. Journal of Environmental Management 223: 668-675.

Sinclair, A. R. E. and Pech, R. P. 1996. Density Dependence, Stochasticity, Compensation and Predator Regulation. - Oikos 75: 164-173.

Stamps, J. A. 1988. Conspecific Attraction and Aggregation in Territorial Species. - The American Naturalist 131: 329-347.

Therneau, T. 2021. A package for Survival Analysis in R. - R package version 3.2-11 <URL: https://CRAN.Rproject.org/package=survival>

Threatened Species Scientific Committee 2015. Conservation Advice Dasyurus viverrinus Eastern Quoll. In: Department of the Environment.

Trochet, A., et al. 2016. Evolution of Sex-Biased Dispersal. - The Quarterly Review of Biology 91: 297-320. Vehtari, A., et al. 2017. Practical Bayesian model evaluation using leave-one-out cross-validation and WAIC. - Statistics and Computing 27: 1413-1432.

Ward, M., et al. 2020. Impact of 2019-2020 mega-fires on Australian fauna habitat. - Nature Ecology \& Evolution 4: 1321-1326.

Weeks, A. R., et al. 2011. Assessing the benefits and risks of translocations in changing environments: a genetic perspective. - Evolutionary Applications 4: 709-725.

Weeks, A. R., et al. 2016. Conservation of genetic uniqueness of populations may increase extinction likelihood of endangered species: the case of Australian mammals. - Frontiers in Zoology 13: 31. 
Wilson, B. A., et al. 2020. Adapting reintroduction tactics in successive trials increases the likelihood of establishment for an endangered carnivore in a fenced sanctuary. - PLOS ONE 15: e0234455.

Wilson, H. B., et al. 2011. When should we save the most endangered species? - Ecology Letters 14: 886890.

Woinarski, J. C. Z., et al. 2011. The disappearing mammal fauna of northern Australia: context, cause, and response. - Conservation Letters DOI: 10.1111/j.1755-263X.2011.00164.x.

Woinarski, J. C. Z., et al. 2015. Ongoing unraveling of a continental fauna: Decline and extinction of Australian mammals since European settlement. - Proceedings of the National Academy of Sciences 112: 4531-4540.

Woinarski, J. C. Z., et al. 2017. The contribution of policy, law, management, research, and advocacy failings to the recent extinctions of three Australian vertebrate species. - Conservation Biology 31: 13-23.

\section{Figures}




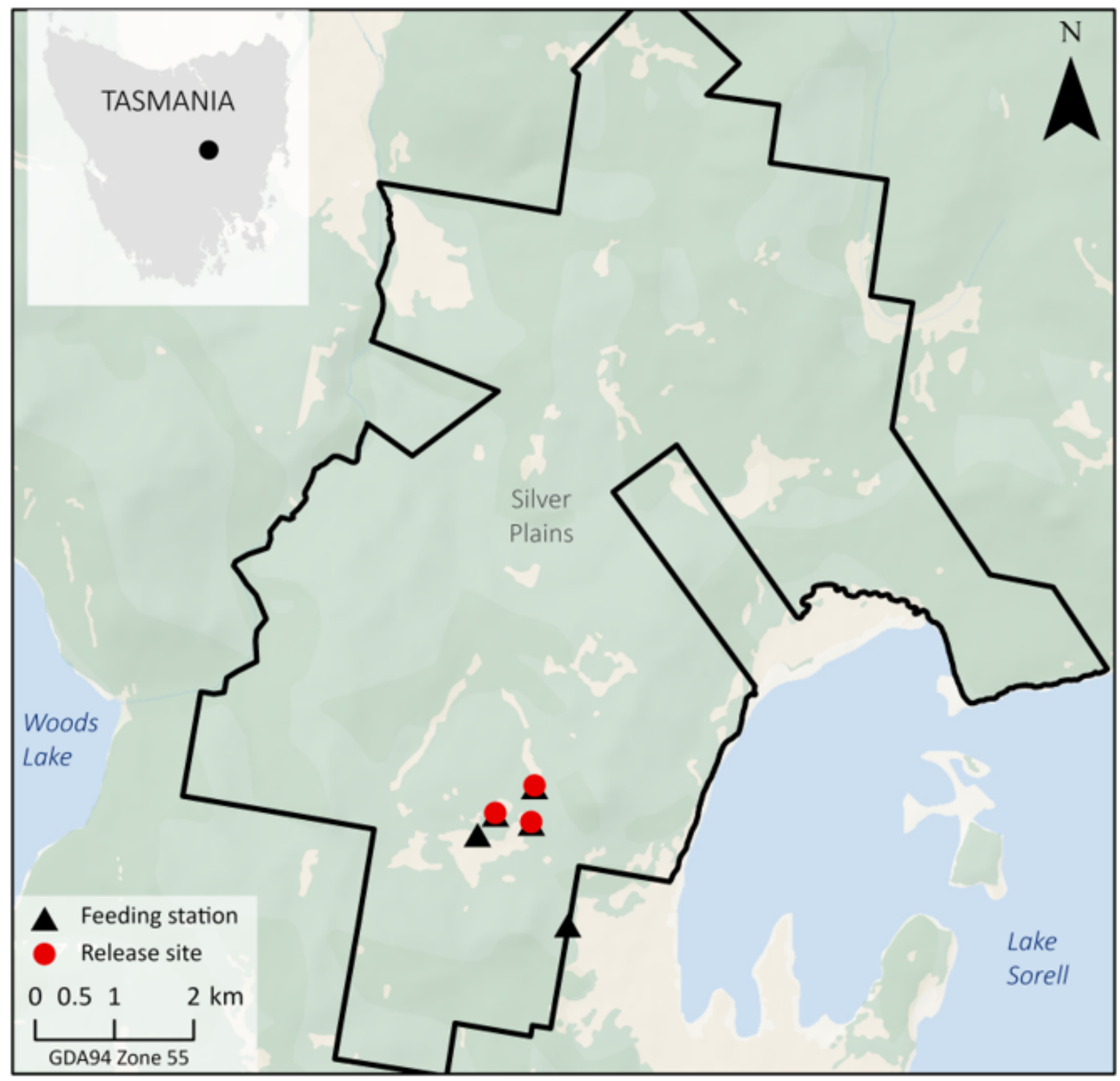

Figure 1

Location (inset) and layout (main map) of Silver Plains study site in the Tasmanian Central Highlands. Release locations are shown as red circles and feeding station locations as black triangles. Green areas on the map represent scrub, forest and woodland vegetation types, while cream areas represent open vegetation types (native grassland, pasture, wetlands and moorlands), derived from TASVEG 4.0 (DPIPWE 2020). 
a) Survival
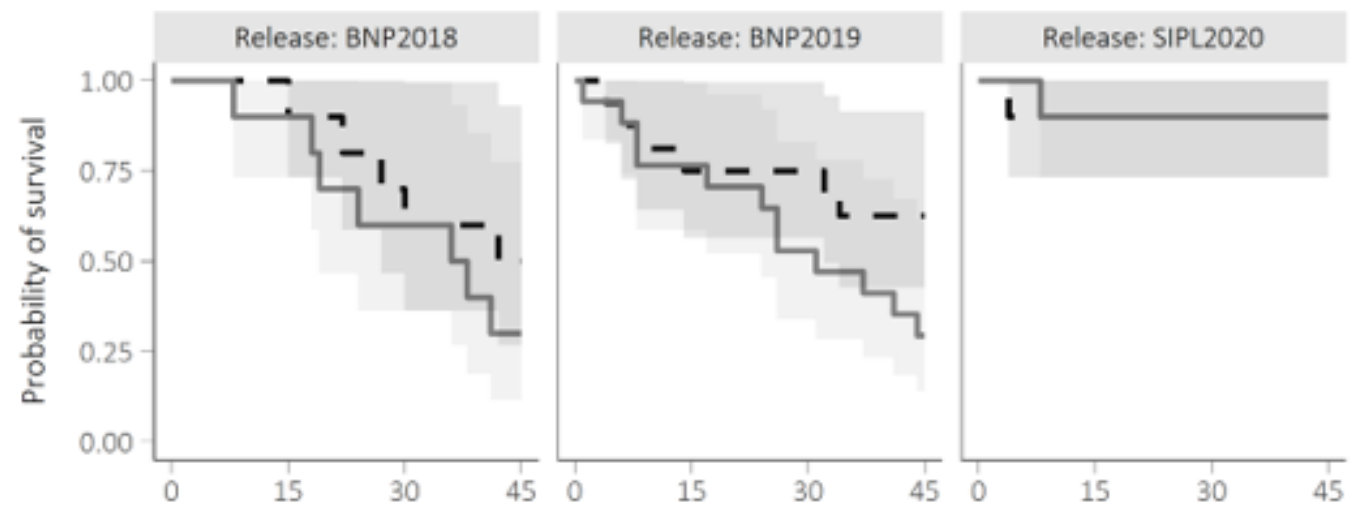

b) Dispersal
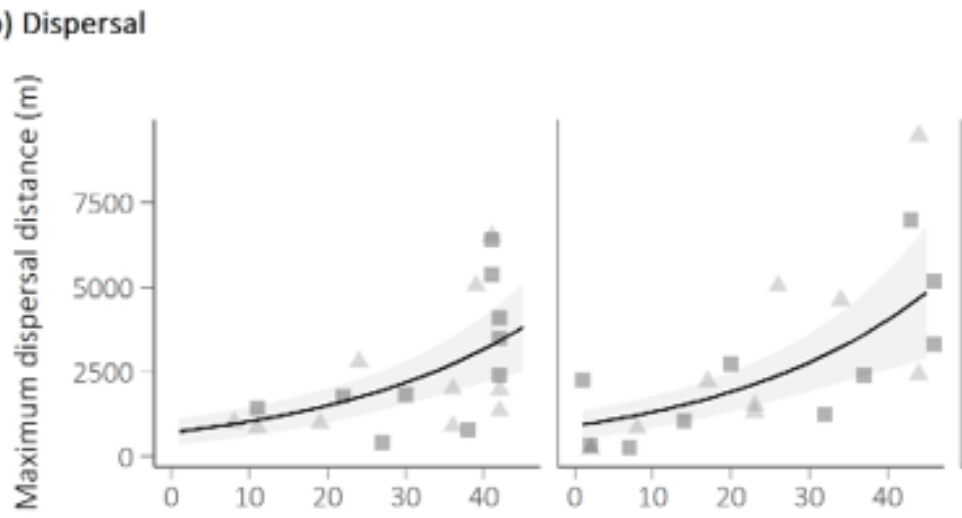

- Female
A Male

c) Body condition

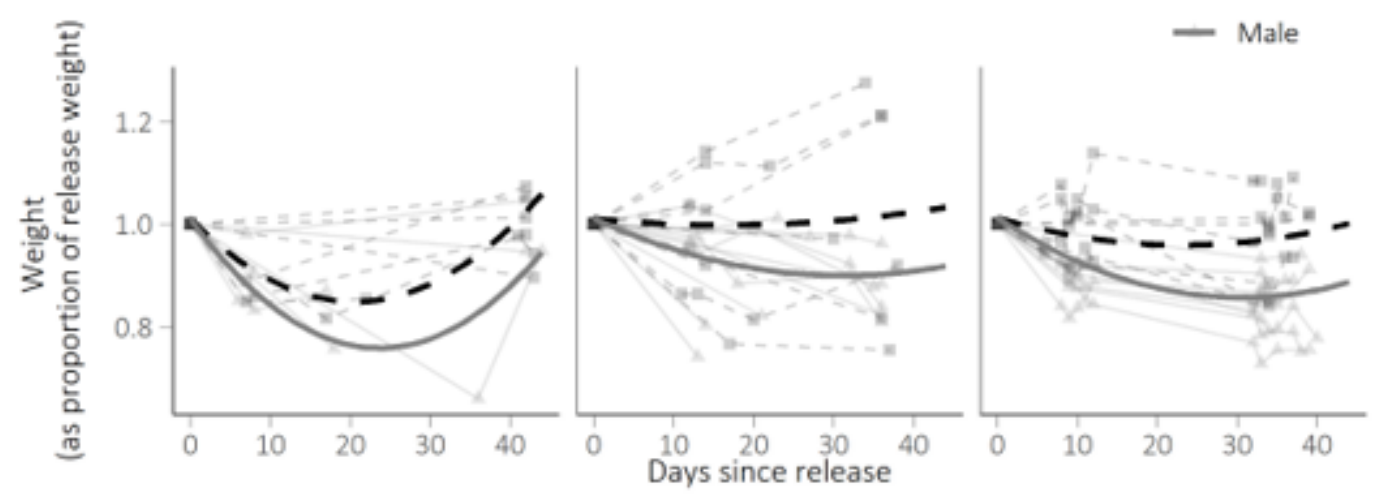

\section{Figure 2}

Differences in short-term survival probability, maximum dispersal and body condition of captive-bred eastern quolls released at Booderee National Park (BNP), NSW in 2018 and 2019 and Silver Plains (SIPL), Tasmania in 2020. Panels show: a) Kaplan-Meier survival curves for females (dashed lines) and males (solid lines) for each release; b) raw data (points) and modelled relationship (lines) between maximum dispersal distance (Euclidean distance between release point and daytime den site) and tracking duration for each release; and c) model predictions for changes in body condition (weight relative to release weight) as bold dashed (female) and solid (male) lines, plotted over raw data for each quoll. Grey shading in top panels indicates the $95 \%$ confidence intervals for model predictions. 


\section{Supplementary Files}

This is a list of supplementary files associated with this preprint. Click to download.

- EQPilot20211223AppendixS1.pdf

- EQS2data20211223.xIsx 